\title{
Inserção do nutricionista na equipe de atendimento ao paciente em reabilitação física e funcional ${ }^{1}$
}

\author{
Insertion of a nutritionist in a team that attends \\ patients requiring physical and functional rehabilitation
}

Tatiana Resende Prado Rangel de OLIVEIRA ${ }^{2}$

Antônio Leite Alves RADICCHI ${ }^{3}$

RE S U M O

\section{Objetivo}

Compreender os motivos e o modo como se deu a entrada do nutricionista na equipe do Centro de Reabilitação CREAB, localizado em Belo Horizonte, MG.

\section{Métodos}

Trata-se de uma pesquisa qualitativa, que tem como desenho o estudo de caso. A pesquisa foi realizada por meio da combinação de instrumentos, como a observação participante, o levantamento de documentos institucionais e o relato oral de profissionais que compõem a equipe.

\section{Resultados}

Constatou-se que os profissionais desse centro acreditam que a assistência nutricional adequada pode prevenir ou limitar as complicações advindas das doenças músculo-esqueléticas, aliviar o desconforto dos pacientes e auxiliar no tratamento de reabilitação.

\section{Conclusão}

A prática do nutricionista dentro dessa equipe abriu e consolidou um espaço para essa categoria profissional, não só na própria unidade, como em outros centros de reabilitação.

Termos de indexação: doenças músculo-esqueléticas, equipe de assistência ao paciente, nutricionista, reabilitação, centros de reabilitação.

\footnotetext{
1 Artigo elaborado a partir da dissertação de T.R.P.R. OLIVEIRA, intitulada "O nutricionista no atendimento multidisciplinar do paciente em reabilitação do Centro de Reabilitação CREAB". Faculdade de Medicina, Universidade Federal de Minas Gerais, 2003.

2 Secretaria Municipal de Saúde, Centro de Reabilitação CREAB. Rua Joaquim Felício, 141, Sagrada Família, 31030-200, Belo Horizonte, MG, Brasil. Correspondência para/Correspondence to: T.R.P.R. OLIVEIRA. E-mail: <trprangel.pro@@newtonpaiva.br>.

3 Departamento de Medicina Preventiva e Social, Faculdade de Medicina, Universidade Federal de Minas Gerais. Belo Horizonte, MG, Brasil
} 


\section{A B S T R A C T}

\section{Objective}

The purpose of the inquiry was to understand the motives and the way in which a nutritionist entered the team working in the Centro de Reabilitação CREAB in Belo Horizonte, State of Minas Gerais, Brazil.

\section{Methods}

The inquiry presents qualitative research based on a case study. The research was carried out using a combination of instruments such as: participative observation, a survey of institutional data and reports by professionals working in the team.

\section{Results}

According to the professionals from Centro de Reabilitação CREAB, adequate nutritional assistance can prevent or limit complications arising from musculoskeletal diseases, relieve the discomfort of patients and show a positive effect on their rehabilitation treatment.

\section{Conclusion}

The nutritionist working in this group initiated and consolidated the possibility of a professional from this category working not only in this particular rehabilitation centre, but also in other rehabilitation centres.

Indexing terms: musculoskeletal diseases, patient care team, nutritionist, rehabilitation, rehabilitation Centers.

\section{N T R O D U ÇÃ O}

A deficiência física refere-se ao comprometimento do aparelho locomotor, que compreende o sistema osteoarticular, o sistema muscular e o sistema nervoso. As doenças ou lesões que afetam quaisquer desses sistemas, isoladamente ou em conjunto, podem produzir quadros de limitações físicas de grau e gravidade variáveis, segundo o segmento corporal afetado e o tipo de lesão ocorrida. Os tipos de deficiência física mais comuns são: amputações, lesão cerebral, lesão medular, miopatias, doenças degenerativas do sistema nervoso central, lesões nervosas periféricas, seqüelas de politraumatismos, distúrbios posturais e doenças da coluna, artropatias, reumatismos inflamatórios das articulações e lesões por esforços repetitivos ${ }^{1}$.

Dentre as deficiências físicas, as doenças músculo-esqueléticas (DME) são responsáveis pelo afastamento do trabalho, invalidez e aposentadoria em faixa economicamente ativa da população. A osteoartrose (OA) é a causa mais freqüente da incapacidade entre as DME em países desenvolvidos e o joelho é o local de envolvimento mais freqüente nos membros inferiores ${ }^{2}$. A incidência da OA é muito elevada, sendo essa doença responsável pela incapacidade laborativa de $15 \%$ da população adulta do mundo ${ }^{3}$. A OA ocupa o terceiro lugar na lista dos segurados da Previdência Social que recebem auxílio doença, estando atrás somente das doenças cardiovasculares e mentais. Colditz ${ }^{4}$, em seu estudo sobre os custos da obesidade, apresenta as DME como o segundo montante de gastos com os pacientes obesos e suas doenças associadas, superadas apenas pelas complicações cardiovasculares.

A OA é uma doença que se caracteriza pelo desgaste da cartilagem articular e por alterações ósseas ${ }^{1}$. À medida que o processo progride, as juntas tornam-se mais rígidas e muitas vezes dolorosas. Por essa razão, as atividades podem ficar restringidas, havendo, assim, tendência de sobrepeso nesse grupo de pacientes, somado ao esforço adicional sobre as articulações afetadas. A articulação do joelho sofre impacto de cerca de seis vezes o peso corporal durante a deambulação, assim, qualquer aumento de peso terá influência marcante nas forças transmitidas ao joelho².

O excesso de peso tem um importante papel no aparecimento, nas manifestações clínicas e na evolução das doenças músculo-esqueléticas 
(DME) 1,2,5. A relevância clínica da associação entre a obesidade e DME tem sido estabelecida em estudos epidemiológicos e relatada em vários trabalhos. Alencar et al. ${ }^{6}$ relata a incidência de lombalgia em trabalhadores associada ao sobrepeso e à obesidade. Must et al. ${ }^{5}$, utilizando dados do National Health and Nutrition Examination Survey (NHANES III), relataram que a prevalência de osteoartrite e outras doenças aumentou agudamente em homens e mulheres obesos, de forma correspondente ao aumento das classes de peso. Dados do estudo epidemiológico NHANES I mostram que mulheres obesas com Índice de Massa Corporal (IMC) entre 30 e 35 correm quase quatro vezes maior risco de $\mathrm{OA}$ do joelho do que as mulheres com IMC menor que 25. Para homens com os mesmos índices de obesidade, o risco estava 4,8 vezes aumentado quando comparados com controles de peso normal².

A perda de peso pode reduzir o risco individual de um paciente desenvolver $\mathrm{OA}^{2}$. A redução de peso, no entanto, é desafiadora para indivíduos com osteoartrite porque a doença limita suas habilidades de aumentar o gasto energético através de exercícios ${ }^{7}$. Porém, quando o peso corporal se aproxima do normal, o paciente com osteoartrite pode experimentar algum alívio do desconforto e da dor e um aumento da atividade física ${ }^{5,7}$.

A importância do trabalho em equipe para a reabilitação do paciente é uma discussão antiga ${ }^{8}$. Porém, apesar de a associação entre estado nutricional e doenças músculo-esqueléticas já estar bem documentada na literatura, poucos estudos trazem referências sobre a participação do nutricionista em equipes de reabilitação de pacientes com doenças físicas e funcionais. Em revisão da literatura, realizada nas bases de dados Medline e Lilacs, no período de 1982 a 2002, apenas dois estudos trouxeram o tema. Felson ${ }^{9}$, em seu estudo sobre terapias não medicinais para osteoartrite, afirma que a integração da abordagem do nutricionista em conjunto com o fisioterapeuta contribui para um tratamento mais efetivo da doença. Messier et al..$^{10}$ apresentam um estudo relacionando à combinação de exercícios e dietoterapia na melhora do quadro de osteoartrite de joelhos.

O Ministério da Saúde, considerando que a assistência ao paciente em reabilitação física exige uma estrutura especializada e hierarquizada de alta, média e baixa complexidade, criou, por meio da portaria ${ }^{\circ} 818$, de 5 de junho de 2001, mecanismos para a organização e implantação das redes estaduais de assistência à pessoa portadora de deficiência física no Brasil ${ }^{11}$. Essa portaria descreve a estrutura física, os profissionais necessários e o suporte de serviços auxiliares de diagnóstico e terapia que cada nível de complexidade deverá ter. É interessante ressaltar que, apesar de a portaria exigir um profissional nutricionista nas equipes de serviços de referência em medicina física e reabilitação (grau III de complexidade), ela não faz referência às atividades que deverão ser exercidas por esse profissional.

O Centro de Reabilitação CREAB é uma unidade de referência em reabilitação física, destinada ao atendimento de pacientes do Sistema Único de Saúde (SUS) em Belo Horizonte, MG. A unidade tem por objetivo geral prestar assistência integral ao paciente portador de déficit motor ou funcional, temporário ou permanente, por meio de uma abordagem multidisciplinar. Sua criação, em 30 de agosto de 2001, surgiu da necessidade de integrar as ações de reabilitação desenvolvidas no município, e de acompanhar e controlar a assistência prestada a esses pacientes ${ }^{12}$. Atualmente, a unidade é referência para autorização de início e continuidade do tratamento de reabilitação para toda a cidade e região metropolitana.

O tratamento ambulatorial caracteriza-se pelo deslocamento do paciente até o serviço de reabilitação, em uma freqüência mínima de três vezes por semana. Esse fato determina, em parte, o perfil da clientela do CREAB: pessoas portadoras de pequena e média incapacidade funcional como conseqüência principalmente de doenças ortopédicas, seguidas pelas doenças traumato- 
lógicas, neurológicas e reumatológicas. A unidade mantém, também, o único centro distribuidor de bolsas para pacientes ostomizados de Belo Horizonte.

O CREAB sempre organizou seu trabalho com a perspectiva da atuação conjunta de diferentes profissionais. A equipe era, inicialmente, composta por fisioterapeutas, terapeutas ocupacionais e assistente social. No decorrer do trabalho, sentiu-se a necessidade de incorporação de outros profissionais a essa equipe. Após a observação de que um grande número de pacientes que procuravam o CREAB apresentava excesso de peso, passou-se a questionar se a inserção de um profissional nutricionista traria benefícios aos pacientes e melhor eficácia ao tratamento desenvolvido nessa instituição.

Foi nessa conjuntura que se deu a inserção do nutricionista no CREAB. Inicialmente, o profissional foi cedido por outra unidade, uma vez por semana. Em pouco tempo, a agenda para consultas de nutrição ficou lotada com os encaminhamentos feitos pelos demais profissionais da equipe. Tornou-se evidente a necessidade da contratação de um nutricionista para o atendimento exclusivo do CREAB.

As indagações iniciais que levaram a este estudo surgiram dessa vivência profissional. Um objeto de estudo, geralmente, surge no espaço de trabalho do pesquisador, a partir das experiências vividas e das reflexões feitas nesse espaço ${ }^{13}$.

A escassez de estudos que abordem o papel do nutricionista na equipe de reabilitação física e orientem as ações da nutrição nesse contexto define a importância deste tema. A finalidade desta investigação é compreender o processo de inserção do nutricionista nessa equipe e, a partir disso, contribuir para a melhoria da qualidade do tratamento em reabilitação.

\section{MÉ T O D O S}

O objeto deste trabalho impôs a metodologia qualitativa como concepção teórica de abordagem, uma vez que ela atende melhor a natureza do problema a ser estudado. A pesquisa qualitativa responde a questões muito particulares e se preocupa com um nível de realidade que não pode ser quantificado ${ }^{14}$.

O desenho da pesquisa escolhido para este trabalho é o estudo de caso, baseado no referencial teórico do interacionismo simbólico. Trata-se de um estudo descritivo, que possibilita compreender melhor um fenômeno em particular, dentro do seu contexto real em uma instituição.

A concepção interacionista concebe a sociedade como um conjunto de indivíduos e grupos em interação, tendo como base o compartilhar de sentidos sob a forma de compreensões e expectativas comuns ${ }^{15}$. No interacionismo simbólico, o sentido das coisas (objetos físicos, outros seres humanos, instituições, atividades dos outros) é modificado por um processo interpretativo consensual ao grupo ${ }^{14,15}$.

O estudo de caso visa sobretudo à profundidade e permite, num primeiro momento, compreender os elementos e o processo que definem a situação. Porém, a análise das informações obtidas na pesquisa pode permitir também tirar conclusões aplicáveis em outros contextos semelhantes ${ }^{16}$.

O universo de análise deste trabalho é composto pelos profissionais que atuam no Centro de Reabilitação CREAB e pela gerência desse centro. A escolha da amostra foi feita com a preocupação de selecionar pessoas diferentes quanto à formação, ao tempo de formadas e ao fato de exercerem ou não atividades acadêmicas. Assim, foram entrevistados trabalhadores de diversas formações técnicas: fisioterapeuta, terapeuta ocupacional, enfermeiro, psicólogo e fonoaudiólogo.

O número de entrevistados não estava totalmente fechado a priori e dependeria do desenvolvimento das entrevistas e da suficiência e esgotamento das informações. Definiu-se, inicialmente, um universo de oito a doze informantes, devido ao fato de que a representatividade de uma amostra selecionada para 
entrevistas baseia-se não só em aspectos quantitativos, mas sobretudo qualitativos ${ }^{17}$. Ao final foram realizadas dez entrevistas.

A observação é uma forma de fazer contato com o real, para situar e orientar os questionamentos, enfim, tem um papel importante na construção do saber ${ }^{16}$. A observação participante é o método por excelência dos estudos interacionistas ${ }^{15}$ e pode ser definida como uma técnica pela qual o pesquisador se integra e participa da vida de um grupo para compreender o sentido a partir dele ${ }^{16}$. A observação do processo de trabalho e das relações profissionais no CREAB deu-se nos dois anos que a autora trabalhou nessa unidade. Foi a partir de tais observações que surgiram as indagações iniciais e a necessidade de descrever e compreender a atuação do nutricionista em reabilitação.

A entrevista é um instrumento de coleta de dados que permite a interação entre o entrevistador e o entrevistado ${ }^{16,17}$. Essa característica é importante, pois nos leva a admitir que nesse processo cada indivíduo é influenciado pelo outro e influencia o outro. Para entrevistar os componentes da equipe, elaborou-se um roteiro com perguntas escolhidas em função do problema estudado. Procurando reduzir o caráter estruturado das entrevistas e torná-las menos rígidas e constrangedoras, optou-se pela técnica de entrevista semi-estruturada, na qual há uma combinação entre perguntas abertas e fechadas e o entrevistado pode discorrer sobre o tema proposto sem condições pré-fixadas rigidamente pelo pesquisador ${ }^{17}$. $\mathrm{O}$ informante fala mais que o pesquisador, mas esse efetua intervenções para trazer o informante aos assuntos que pretende investigar. Quem orienta o diálogo é o pesquisador que, para usar essa técnica, necessita dispor de conhecimento anterior sobre o tema ${ }^{16}$.

As entrevistas foram feitas pelo próprio pesquisador, utilizando a técnica de gravador e bloco de anotações de campo. O caderno de campo completou as informações não gravadas, referentes às condições em que foram feitas as entrevistas e aos detalhes descritivos e pessoais acerca do entrevistado. Todos os entrevistados foram contactados previamente, quando se fez a apresentação dos propósitos da pesquisa e solicitou-se o agendamento da entrevista. As fitas gravadas foram transcritas na íntegra, seguindo-se a recomendação de Queiróz ${ }^{17}$, que define a transcrição como a reprodução de um documento, em total conformidade com sua primeira forma, sem nada que o modifique. Ainda, segundo a orientação da mesma autora, as fitas foram transcritas pelo próprio pesquisador.

Os documentos que dão suporte legal ao trabalho - portarias do Ministério da Saúde, editais da Secretaria Municipal de Saúde, Manual de Diretrizes Operacionais sobre a Organização de Serviços, documentos internos do CREAB e instruções de serviço da Prefeitura de Belo Horizonte - foram coletados na Secretaria Municipal de Saúde, no Distrito Sanitário Leste e no próprio CREAB.

O método de análise empregado foi de natureza qualitativa, baseado em Minayo ${ }^{13,14}$, Haguette $^{15}$, Laville \& Dionne ${ }^{16}$, Queiróz ${ }^{17}$ e Simioni et al. ${ }^{18}$.

O procedimento para análise das entrevistas consistiu da leitura e releitura de cada um dos relatos transcritos. As entrevistas foram identificadas pela letra " $E$ ", seguida de um número de um a dez. Inicialmente realizou-se a leitura vertical das entrevistas, buscando conhecer, através da fala dos sujeitos da pesquisa, suas representações sobre o problema estudado. Depois procedeu-se à leitura horizontal do conjunto dos relatos sobre cada questão proposta, a fim de identificar os aspectos recorrentes e os contraditórios para perceber as diferentes formas em que o mesmo tema aparece, tentando captar as percepções dos sujeitos referentes a cada questão. Após várias leituras, agruparam-se os temas principais, procurando-se compreender os significados que os sujeitos enunciam com o objeto de estudo. A análise prosseguiu, então, no processo de discussão das informações bibliográficas de outras pesquisas relativas ao mesmo tema em foco. 


\section{RES ULTADOS}

Como citado anteriormente, a história do CREAB é caracterizada pelo constante desejo de compor uma equipe para o atendimento integral do paciente em reabilitação. Percebia-se a necessidade da atuação em conjunto com outros profissionais cujo objeto de trabalho fosse direcionado para outros fatores que determinam o processo saúde-doença. Os entrevistados relataram ainda o desejo de oferecer uma prática mais resolutiva ao paciente. Foi dentro dessa perspectiva que se deu a inserção do nutricionista.

Na verdade, já tínhamos uma preocupação de que o trabalho isolado da fisioterapia não significa muito; precisávamos destes outros profissionais para complementar o trabalho (E2).

Nas diversas conversas que a gente tinha as profissionais sempre colocavam os limites de sua atuação. Também já faziam algumas associações entre os tipos de padecimento, de sofrimento, de fatores que tinham interferência no trabalho delas e relatavam uma insatisfação com o alto grau de cronicidade presente no serviço (E3).

Porém, quando se analisam os motivos específicos pelos quais os profissionais sentiam a necessidade de atuar em conjunto com o nutricionista, encontram-se justificativas diferentes. Mas, sem dúvida, a maior preocupação era com a interferência do estado nutricional no processo da doença instalada e na própria evolução do tratamento, conforme demonstrado pela fala dos entrevistados:

[...] acho que uma coisa fundamental para termos pensado no nutricionista para completar esta equipe foi por causa das doenças osseodegenerativas, artrose de joelhos e lombalgias; porque a gente tinha um número muito grande de pacientes obesos, ou com excesso de peso. A gente não sabia o que fazer (E2).

[...] esses pacientes mais obesos chegavam aqui naquela canseira, a gente via que as sessões não rendiam, eles não se movimentavam, e o fisioterapeuta sempre lhes dizendo que emagrecer ajudaria no tratamento. Mas eles não tinham esta orientação. Esses pacientes falavam: tudo para o gordo é mais difícil (E8).

Como o Programa de Ostomizados está inserido no trabalho do centro de reabilitação CREAB, o profissional que trabalha neste programa apontou a necessidade do nutricionista nesta equipe, com um propósito mais específico:

[...] uma das coisas que acontece com o paciente ostomizado, além da retirada de um órgão importante, é que ele vai ter que conviver também com odores, com flatulência, com diarréia, com constipação. Então, o nutricionista não pode faltar na equipe (E6).

A nutrição exerce um papel fundamental na promoção da saúde dos indivíduos e na redução dos fatores de risco para o desenvolvimento de doenças. É interessante notar que alguns componentes da equipe já percebiam essa importância do papel preventivo da orientação nutricional:

Eu entendo como uma medida preventiva e é o melhor negócio (E4).

E eu acho que vocês entram numa questão que é muito legal; não é só a recuperação do paciente, mas também a prevenção de um novo derrame (E7).

Mas a percepção da necessidade da participação específica do nutricionista não foi comum a todos. Ela se deu em graus e em momentos diferentes. E nesse processo o envolvimento dos profissionais do CREAB também foi diferente,o que é confirmado por alguns entrevistados:

Eu não me lembro bem de quando foi a entrada do nutricionista na equipe...eu sentia falta do nutricionista era quando eu trabalhava com hipertensos em atenção primária. No CREAB eu nem prestei muita atenção (E9).

Eu acho que entendimento todos têm. 
As pessoas diziam que seria bom ter 0 profissional. Mas, não fariam nenhum movimento para trazer A ou B para cá (E3).

A única pessoa do CREAB que já havia trabalhado com o nutricionista foi a gerente. Assim, era de esperar que houvesse uma dificuldade inicial de entendimento quanto ao objeto de trabalho desse profissional:

[...] eu não tinha muita clareza de como é que o profissional ia se inserir na equipe, como que, na prática, iria se dar a integração com o fisioterapeuta (E5).

Eu não tinha idéia que havia este profissional na prefeitura e sua importância.....e o tanto de benefícios que vocês trariam para a gente...no meu trabalho... (E1).

Tendo sido discutida essa necessidade, a equipe criou a demanda desse profissional. Nesse momento, o empenho pessoal da gerente da unidade foi imprescindível. Essa percepção é referendada pelo discurso dos entrevistados:

Havia uma demanda, um interesse, uma visão da importância do nutricionista na equipe. Acho que a equipe estava bem antenada e, individualmente, tanto a fisioterapia, a terapia ocupacional e a própria visão da gerente já trazia isto da importância, do valor da nutrição na Equipe de Reabilitação (E7).

[...] eu entendi que era uma demanda da equipe. Acho que, inicialmente, não foi uma coisa formulada no sentido precisamos disto e daquilo. A gente conseguiu ir amadurecendo (E3).

Outros fatores também se mostraram facilitadores nesse processo de inserção do nutricionista, como o apoio da Secretaria Municipal de Saúde e a possibilidade de pedir extensão de jornada para um nutricionista que já estava desenvolvendo um trabalho, ainda que pequeno, no CREAB.

Quando, finalmente, esse profissional foi agregado à equipe, os demais componentes acharam que a idéia foi interessante e veio, então, ao encontro dos objetivos que já haviam sido traçados para aquela unidade:

Achei importante porque foi uma parceria. E eles precisavam deste tipo de orientação, porque, eu acho que, sozinhos, eles não tinham noção (E8).

Achei muito interessante; trouxe segurança, trouxe uma visão muito diferenciada, inovadora da Nutrição, porque, por mais interesse que a gente tenha, nem sempre se tem a melhor informação sobre determinada profissão (E7).

A maioria dos nossos pacientes é muito carente mesmo. Se você for pensar, os planos de saúde não dão esta cobertura, a não ser em casos de internação hospitalar. Então, isto, ainda, é um trabalho muito novo e, nesse aspecto, eu fico muito feliz da gente poder contar com este serviço aqui; de ver que os nossos resultados são palpáveis em muitos casos e de estar oferecendo esta possibilidade para pessoas que, de outra maneira, nunca teriam contato, nem passariam na porta de um nutricionista (E3).

Com a experiência do trabalho de parceria entre os profissionais que tradicionalmente compõem a equipe de reabilitação e um ator novo nesse cenário, algumas questões se mostraram importantes. A entrada do nutricionista na equipe provocou mudanças na prática de alguns profissionais, o que é demonstrado pelas falas abaixo:

[...] as pessoas começaram a observar ganhos, se tornou uma prática, uma agenda extremamente concorrida. Hoje, como a gente já tem a presença dessa categoria profissional aqui dentro, não ter agenda para eles é complicado (E3).

Trabalhar com o nutricionista confirmou o que eu imaginava da importância dele trabalhar junto com a fisioterapia na reabilitação do paciente. $\mathrm{Vi}$ isto muito claramente. A dieta passada pelo nutricionista é importante. O jeito que 
eu falava de dieta não era correto, não era adequado (E2).

Quanto à importância da inserção do nutricionista na equipe, os entrevistados relataram que esse profissional tem seu lugar bem marcado no trabalho de reabilitação:

O espaço do nutricionista é muito claro e necessário também (E1).

É de fundamental importância! Neste local tem a demanda e tem a necessidade. Tanto é que quando a agenda está lotada a gente fica sem saber o que fazer com os pacientes... (E2).

[...] mas para a grande maioria dos pacientes do Programa de Ostomizados, não existe reabilitação se não tiver o nutricionista (E6).

Porém, conforme lembrou um dos entrevistados, dentro dos serviços públicos de saúde os gestores não têm essa visão do profissional nutricionista e não compreendem o seu papel na saúde pública:

Olha, eu acho que a maioria não sabe do que se trata. São pouquíssimos profissionais na rede, e o impacto deste trabalho é muito pequeno! Por exemplo, falar que o nutricionista está na Secretaria de Abastecimento, as pessoas acham que é natural. Agora, na saúde, dentro de uma equipe, o que poderia ser feito... (E3).

E, aí, eu cobro dos profissionais também, que poderiam estar fazendo mais pressão, mostrar o que está realizando, fazendo um movimento que mostrasse essa importância, para fazer aumentar o número de profissionais, ter o reconhecimento. Mas, também isto é um processo (E3).

Eu acho que é um círculo vicioso. A população está sempre falando de médico, de enfermeiro; a própria imprensa também. Então, é um trabalho que não está restrito à Secretaria Municipal de Saúde, mas também aos conselhos de classe, às faculdades, que têm que estar criando este espaço. Porque passa muito esta imagem de profissional de elite. A imprensa faz entrevista tipo como se alimentar no período de carnaval, ou joga na mídia matérias sobre os SPAS...sempre esta visão fora da Saúde Pública (E3).

A expectativa inicial dos profissionais ao encaminhar um paciente para a nutrição está relacionada com o motivo pelo qual ele fez essa escolha, com o objetivo que ele tinha. Assim, como a maioria dos encaminhamentos é feita visando à redução do peso, a expectativa principal é realmente a do emagrecimento, como confirmado pelos entrevistados:

[...] a maioria, era por excesso de peso mesmo e a minha expectativa inicial era a redução do peso. Mas, eu sei que tem outras coisas também que eles vão ganhar (E5).

[...] que ela siga mesmo a dieta da nutrição e consiga mesmo emagrecer. Espero muito dela, porque ela precisa (E1).

Com relação ao paciente ostomizado, a expectativa estende-se para a questão emocional do paciente.

“...melhorando a diarréia, a lesão de pele também melhora, a bolsa não vai soltar o tempo todo e o paciente terá mais segurança" (E6).

Porém, alguns profissionais relataram esperar a orientação técnica correta, acessível e dentro da realidade do paciente. Outros ainda conseguiram visualizar um ganho maior para o paciente, que é a questão da reeducação alimentar, conforme se vê nos discursos:

[...] a expectativa é de que ele tenha orientação, dentro da sua capacidade de compreensão (E7).

O principal, é que quero que o paciente entenda o que é uma dieta e qual é a importância de fazê-la...e também que não é difícil ele seguir as orientações, fazer uma reeducação alimentar (E2).

[...] que o nutricionista informe para ele o que deve ou não comer e o que pode levá-lo a ter outro derrame. Que ele 
tenha esta orientação toda, minuciosa. Eu vejo nossos pacientes com um poder aquisitivo baixo, cognitivo também. Então, esta possibilidade de poder fazer uma troca de alimentos...se ele não puder comprar (E4).

\section{DISCUSS Ã O}

O conceito de reabilitação reúne um grande número de definições e há uma tendência na literatura em confundi-lo com o de ajustamento e recuperação, no sentido de consertar, reparar. A reabilitação é um processo singular, que visa desenvolver as potencialidades do paciente e conduzi-lo a uma vida com qualidade ${ }^{19}$. No entanto, essa visão abrangente, que busca unir reabilitação e qualidade de vida, é relativamente recente dentro dos serviços públicos de saúde. Durante muitos anos, reabilitação e fisioterapia, para pacientes e gestores, foram consideradas sinônimas e isso contribuiu para a não disponibilização de outros recursos terapêuticos ${ }^{20}$. Uma visão mais totalizadora do paciente, associada a um trabalho interdisciplinar harmonioso, possibilitará uma resposta terapêutica mais favorável no tratamento em reabilitação ${ }^{21,22}$.

Após a leitura dos depoimentos apresentados, podemos perceber que havia, entre os profissionais do $C R E A B$, a preocupação com os limites do trabalho isolado do fisioterapeuta e um desejo de oferecer uma prática mais resolutiva aos pacientes. Esse fato tem respaldo em estudos que mostram que em muitas clínicas de fisioterapia pode-se observar a cronificação de certos casos, a persistência de dor e queixas associadas e a limitação aos movimentos, que levam os fisioterapeutas a uma insatisfação e incerteza quanto a sua performance profissional21,22.

Os profissionais do CREAB não sabiam exatamente como seria a interface do trabalho com a nutrição, mas estavam em busca de recursos para auxiliar sua práxis. Assim, parecenos que o fato dessa equipe estar aberta a novos recursos de trabalho possibilitou a discussão em torno da inserção desse novo agente. A necessi- dade de incluir o nutricionista veio com a percepção da interferência do estado nutricional no processo da doença $a^{2,5}$ e na evolução do tratamento ${ }^{20}$, principalmente entre pacientes obesos, cujas sessões tinham baixo rendimento. Apesar das dúvidas quanto ao processo de trabalho do nutricionista, a equipe do CREAB foi pioneira em perceber a necessidade de inserir esse profissional no atendimento em reabilitação, antes até da exigência legal ${ }^{11}$.

As relações sociais que se estabelecem entre os diferentes agentes em uma equipe de saúde não estão livres de tensões e discordâncias, como em todas as relações. Segundo Peduzzi²3, tanto as desigualdades entre os variados trabalhos e os respectivos agentes que os executam como a relação hierárquica entre os trabalhadores refletem conflitos no trabalho em equipe multiprofissional. Assim, tradicionalmente, falta aos profissionais de saúde a percepção de que estão em interação no trabalho, o que dificulta a construção de outros projetos com base no objetivo comum. Tal fato não se dá no CREAB. Ao elegerem o objetivo comum de atuar além da doença, os entrevistados parecem buscar a multidimensionalidade do objeto de trabalho de cada área profissional.

Os resultados alcançados por uma equipe de saúde dependem de como os seus componentes assumem ou não sua condição de grupo. O trabalho em equipe configura-se como possibilidade de recomposição dos trabalhos especializados por meio da interação. Uma característica importante do trabalho em equipe é a elaboração conjunta de linguagens, objetivos e propostas comuns $^{23}$.

Observa-se, na equipe do Centro de Reabilitação CREAB, um interesse comum pela melhoria da qualidade de atenção ao paciente. Observa-se, ainda, uma situação de trabalho coletivo sem desigualdade entre os agentes, o que possibilita uma maior integração na equipe. 0 respeito pelo saber do outro é um fator essencial para a ocorrência de diálogo entre os vários saberes. Essas características da equipe do CREAB 
possibilitam compreender como se deu a inserção do nutricionista nesse atendimento. A preocupação central dos profissionais era oferecer um tratamento mais resolutivo ao paciente. A recompensa por esse trabalho manifesta-se através da satisfação em poder contribuir para a solução de um problema comum, ou seja, a melhoria da qualidade de atendimento ao paciente.

As mudanças que ocorrem na composição de uma equipe levam a alterações nos processos de trabalho e no modo de organizar os serviços ${ }^{23}$. Os profissionais do CREAB relataram mudanças no trabalho após a entrada do nutricionista, as quais apontam para o reconhecimento do seu espaço de trabalho, do seu diferencial do saber $e$ dos resultados alcançados. A expectativa quanto a esse atendimento é de que o paciente melhore o seu estado nutricional, uma vez que isso irá interferir positivamente no tratamento da reabilitação física. Espera-se também que o paciente receba orientação para fazer mudanças no seu hábito alimentar, dentro da sua realidade econômica e capacidade cognitiva. Nota-se ainda uma grande preocupação com a possibilidade de prevenção de um novo acidente vascular cerebral (AVC) e outras seqüelas decorrentes do diabetes, hipertensão e dislipidemias.

A ampliação dos campos de atuação profissional tem sido uma conquista dos nutricionistas nas últimas décadas ${ }^{24}$. O campo da saúde pública apresenta para eles uma oportunidade de trabalhar com maior autonomia. Diferentemente do que acontece em outras áreas de atuação desse profissional, as relações de trabalho não se mostram tensas e as questões ligadas à divisão do trabalho no interior das equipes são mais diluídas ${ }^{25}$. Sendo assim, caberia a nós questionar o motivo do baixo número de nutricionistas nos serviços públicos de saúde e sua ausência nas equipes de atenção ao paciente em reabilitação física. Há uma grande necessidade de ações de educação nutricional nesses serviços, porém o espaço institucional não existe ${ }^{26}$.

O nutricionista é o profissional habilitado por formação para adequar as orientações alimentares à realidade dos pacientes ${ }^{27}$. De acordo com esta pesquisa, os profissionais do CREAB reconhecem o espaço de trabalho desse profissional no campo da educação nutricional. Os entrevistados relatam, porém, que a maioria dos gestores desconhece o papel do nutricionista na saúde pública, sendo a imprensa divulgadora de uma visão de "profissional de elite", por isso, para Boog $^{26,27}$, a atuação do nutricionista nessa área precisa ser esclarecida, divulgada e incentivada.

Fica aqui, então, uma dúvida quanto a quem caberia a responsabilidade de esclarecer $\mathrm{e}$ divulgar o papel do nutricionista na reabilitação, pois, em virtude da portaria 818 do Ministério da Saúde, esse profissional se tornou parte da equipe mínima para centros de referência em reabilitação na saúde pública ${ }^{11}$. Portanto, é pertinente que a categoria se organize para essa discussão.

\section{CONCLUSÃO}

O objetivo desta pesquisa era levantar questões relacionadas à introdução de um novo ator na equipe de assistência ao paciente em reabilitação física. O modelo biomédico de atenção a esses pacientes, com sua visão simplificada do problema, tem comprometido a eficácia da atenção em reabilitação ao desconsiderar os múltiplos fatores que contribuem para o processo de adoecer. Considerou-se ainda que esse seria um tema de interesse para todos os nutricionistas, uma vez que esse agente ainda está em fase de construção da sua identidade profissional.

A experiência de ampliação de qualquer serviço de saúde demonstra que a demanda, até então desconhecida, tende a se deslocar em busca do acesso facilitado. Não ocorreu de forma diferente com o CREAB. Com a introdução desse novo serviço - $O$ atendimento nutricional - houve um redirecionamento do fluxo de atendimento no sentido de agregar mais esse valor ao tratamento em reabilitação. De maneira geral, a presença do nutricionista na equipe do CREAB trouxe mudanças na forma de organização do trabalho e contribuiu para uma melhor atenção ao paciente. 
A prática do nutricionista, no decorrer do ano em que ele esteve ligado ao CREAB, abriu e consolidou um espaço para essa categoria profissional não só na unidade, como em outros centros de reabilitação que irão trabalhar dentro das instruções da portaria 818.

A abordagem nutricional pode auxiliar a recuperação dos pacientes em reabilitação. No entanto, é necessária uma divulgação dos resultados alcançados nessa área. Só assim será possível acrescentar ao paciente mais esse apoio em seu processo de reabilitação.

\section{REFERÊ N CIAS}

1. Schnitzer TJ. Osteoartrose. In: Bennett JC, Plum F. Cecil. Tratado de medicina interna. 20.ed. Rio de Janeiro: Guanabara Koogan; 1997. p.1677-85.

2. Radominski SC. Obesidade e doenças músculo-esqueléticas. Rev Bras Reumatol. 1998; 38(5):275-8.

3. Marques AP, Kondo A. A fisioterapia na osteoartrose: uma revisão da literatura. Rev Bras Reumatol. 1998; 38(2):83-90.

4. Colditz GA. Economic costs of obesity. Am J Clin Nutr. 1992; 55(2 Suppl):503S-7.

5. Must A, Spadano J, Coakley EH, Field AE, Colditz G, Dietz WH. The disease burden associated with overweight and obesity. JAMA.1999; 282(16):523-9.

6. Alencar MCB, Petroski EL, Gontijo LA. Avaliação preventiva: um enfoque sobre os distúrbios osteomusculares em trabalhadores de cabinas de arrecadação. Reabilitar. 2001; 13(1):8-15.

7. Shils ME, James AO, Shike M, Ross AC. Tratado de nutrição moderna na saúde e na doença. 9.ed. São Paulo: Manole; 2003.

8. Boccolini F. Importância do trabalho de equipe em reabilitação. Rev Paul Med. 1953; 42(5):364-67.

9. Felson DT. Nonmedicinal therapies for osteoarthritis. Bull Rheum Dis. 1998; 47(2):5-7.

10. Messier SP, Loeser RF, Mitchell MN, Valle G, Morgan TP, Rejeski WJ, et al. Exercise and weight loss in obese older adults with knee osteoarthritis: a preliminary study. J Am Geriatr Soc. 2000; 48(9):1062-72.

11. Brasil. Ministério da Saúde [homepage on the Internet]. Brasília; 2001. [acesso 2002 fev. 22]. Portaria Técnica n 818 GM de 5 de junho de 2001. Dispõe sobre organização e implantação de Redes estaduais de assistência à pessoa portadora de deficiência física. Disponível em: http://www.saude.gov.br/sas

12. Prefeitura Municipal de Belo Horizonte, Instrução de Serviço ${ }^{\circ} 005$ de 30 de agosto de 2001 cria a unidade administrativa Centro de Reabilitação - CREAB. Diário Oficial do Município.

13. Minayo MCS. Pesquisa social: teoria, método e criatividade. 6.ed. Petrópolis: Vozes; 1994.

14. Minayo MCS. O desafio do conhecimento. 6.ed. São Paulo: Hucitec; 1999.

15. Haguette TMF. Metodologias qualitativas na sociologia. 5.ed. Petrópolis: Vozes; 1997.

16. Laville C, Dionne J. A construção do saber: manual de metodologia da pesquisa em ciências humanas. Porto Alegre: Artmed; 1999.

17. Queiróz MIP. Variações sobre a técnica de gravador no registro da informação viva. São Paulo: FFLCH/USP; 1983.

18. Simioni AMC, Lefévre F, Pereira IMTB. Metodologia qualitativa nas pesquisas em saúde coletiva: considerações teóricas e instrumentais. São Paulo: Edusp; 1996.

19. Souza RM, Dias A, Scatena MCM. Reabilitação: uma análise do conceito. Nursing. 2001; 34(4):26-31.

20. Oliveira TRPR. O nutricionista no atendimento multidisciplinar do paciente em reabilitação do Centro de Reabilitação CREAB [dissertação]. Belo Horizonte: Faculdade de Medicina; 2003.

21. Marinho PEM. A visão sistêmica na fisioterapia. Fisioter Mov. 1999; 12(2):9-14.

22. Santos VLCG, Miyadahira AMK, Kimura M Assistência em reabilitação: um processo marcado por deficiências. Rev Gaúcha Enferm. 1990; 11(2):5-11.

23. Peduzzi M. Equipe multiprofissional de saúde: a interface entre trabalho e interação [tese]. Campinas: Faculdade de Ciências Médicas, Universidade Estadual de Campinas; 1998.

24. Vasconcelos FAG. O nutricionista no Brasil: uma análise histórica. Rev Nutr. 2002; 15(2):127-38.

25. Bosi MLM. Profissionalização e conhecimento: a nutrição em questão. São Paulo: Hucitec; 1996.

26. Boog MCF. Educação nutricional em serviços públicos de saúde. Cad Saúde Pública. 1999; 15 Suppl 2:139-38.

27. Boog MCF. Dificuldades encontradas por médicos e enfermeiros na abordagem de problemas alimentares. Rev Nutr. 1999; 12(3):261-72.

Recebido para publicação em 14 de abril de 2004 e aceito em 10 de janeiro de 2005 . 